\title{
NATIONAL ROADMAP FOR SCIENTIFIC INFRASTRUCTURE IN BULGARIA - OPPORTUNITY FOR CARRYING OUT RESEARCH IN THE FIELD OF SOCIAL SCIENCES IN BULGARIA
}

\author{
Radka P. Ivanova \\ Assoc. Prof. Dr., University of Economics Varna, Bulgaria, r.ivanova@ue-varna.bg
}

\begin{abstract}
Carrying out research is an expensive and lengthy process. In Bulgaria, educational and research institutions have limited budgets, which in most cases hinder research. It is possible to address this problem by implementing open innovations to work together. A prerequisite for their implementation is the developed National Roadmap for Scientific Infrastructure in Bulgaria 2020-2027.

The purpose of this article is to analyze the possibilities provided by the National Roadmap for Scientific Infrastructure in Bulgaria 2020-2027 for the implementation of innovative research in the field of social sciences.
\end{abstract}

Keywords: Roadmap, Bulgaria, Scientific Research, Open Innovation.

\section{INTRODUCTION}

The creation of research requires the establishment of an appropriate environment in which different educational and research structures can actively interact. The country in whose capacity is to develop the necessary regulatory base promoting innovative research and their implementation is of the utmost importance. In this regard, a National Smart Specialisation Strategy was developed in Bulgaria, which together with the operational programs of the Structural and Cohesion Funds of the European Union (EU) stimulates innovation activity in the country and focuses on expanding the range of participants in it. Research and education institutions are at the forefront of this strategy, as research underpins innovation. Research is inherently interdisciplinary in nature, which implies the development of an appropriate environment for its implementation. In this context, it is important to build research infrastructure that is limited to the pool of facilities, resources, and related services that are used by the scientific community to conduct high-level research in the fields concerned and cover large-scale research facilities, integrated small research facilities and high-speed communication networks with high-performance computing capacity, networks of computing systems, etc.; knowledge-based resources, such as collections, databases, archives, and other types of structured scientific information; infrastructure competence centers that provide services to wider research communities, as well as any other site of unique nature essential to achieving research excellence (National Roadmap 2017).

\section{NATIONAL ROADMAP FOR SCIENTIFIC INFRASTRUCTURE IN BULGARIA}

The developed European Map for the Establishment of a Pan-European Research Area requires each EU Member State to also develop its national map. In this regard, in Bulgaria in 2010, the first National Roadmap for Scientific Infrastructure (NRSI) was established by the decision of the Council of Ministers. It defines modern scientific fields, ensuring open access to the laboratories concerned. In line with the 
'National Smart Specialisation Strategy 2020' and the priorities of the 2014-2020 programming period, this Roadmap of Bulgaria is undergoing an update to define the objectives of progress, consensus-building between funding institutions and academia, setting two main tasks (StrategicDocuments):

- Task 1: Support research development policy in Bulgaria.

- Task 2: Ensure financialization and transparency to implement the 2014-2020 roadmap.

On the threshold of the new programming period, the Council of Ministers in Bulgaria is also developing a new version of the National Roadmap for Scientific Infrastructure 2020-2027. Its main purpose is to improve the system of scientific and research infrastructures in Bulgaria, overcome the fragmentation of research, create prerequisites for improving the qualification of scientists in the country.

In order to clarify the nature of the NRSI, it is necessary to categorize scientific infrastructures according to their importance, in connection with which the following five groups are established:

- International research infrastructures.

- Unique scientific facilities.

- Bulgaria in pan-European research infrastructures such as the European Strategic Forum for Scientific Infrastructure.

- National scientific innovation complexes - projects with key importance for the development of the competitiveness of the Bulgarian economy and technological base.

- E-infrastructures. Digital, computational, and computer research (e-research).

In this regard, a total of 50 sites are included in Bulgaria's new NRSI, including 15 Centres of Excellence and Competence, as well as 12 new sites. As a result, there are different areas of action covering energy; environment and ecology; biotechnology, biomedicine, health, and food; physics and engineering sciences; aerospace and defense industries; social and cultural innovations, information and communication technologies, including and electronic infrastructure (NPKNIfrast-i-dokladMS).

We must point out that, in practical terms, the implementation of this NPCC in the context of the Bulgaria 2030 programming period is divided into three stages, namely:

First stage: "Increased participation in Horizon Europe, internationalization and national capacity building (2020-2023)", oriented towards the construction and maintenance of existing infrastructure sites.

Second stage: "Building the link with innovation (2024-2025)", focusing on the development of infrastructures and assessing their effectiveness and efficiency in terms of the services they offer, the potential to attract business users, as well as the potential for sustainability and autonomy.

Third stage (2026-2027), which provides for an emphasis on technological transfer, increasing clusters and turning them into technological infrastructures. The attraction of foreign scientists and organizations, the creation of an environment attractive to consumers, and the career development of scientists are at the forefront. In support of these objectives is the ability to create digital access to the services offered by infrastructure.

\section{INFRASTRUCTURE FORMATIONS IN THE FIELD OF SOCIAL SCIENCES IN BULGARIA IN THE CONTEXT OF NRSI}

The analyses of the existing research infrastructure in Bulgaria and the scientific equipment in the country show in general their insufficient development. In general, the conclusions are limited to the following (Diagnostic_BG):

- Insufficiently modern infrastructures to be eligible for modern infrastructure;

- Inefficient loading and maintenance of existing scientific facilities;

- Uneven distribution of scientific infrastructure in territorial and thematic terms;

- Lack of sufficiently qualified staff to maintain scientific equipment;

- Financial instability and lack of business engagement.

As a major problem, human resources are being brought out, namely the lack of sufficient ones with the 
necessary qualifications and desire for research. In this regard, the analysis of Infostat Bulgaria's data for the period 2014-2019 showing the number of staff employed in scientific research and development shows that the highest share is distinguished in the field of technical sciences, followed by the medical and natural sciences, which change their place in different years. The humanities and social sciences are distinguished by the lowest proportion of people engaged in scientific research and development (see Fig. 1).

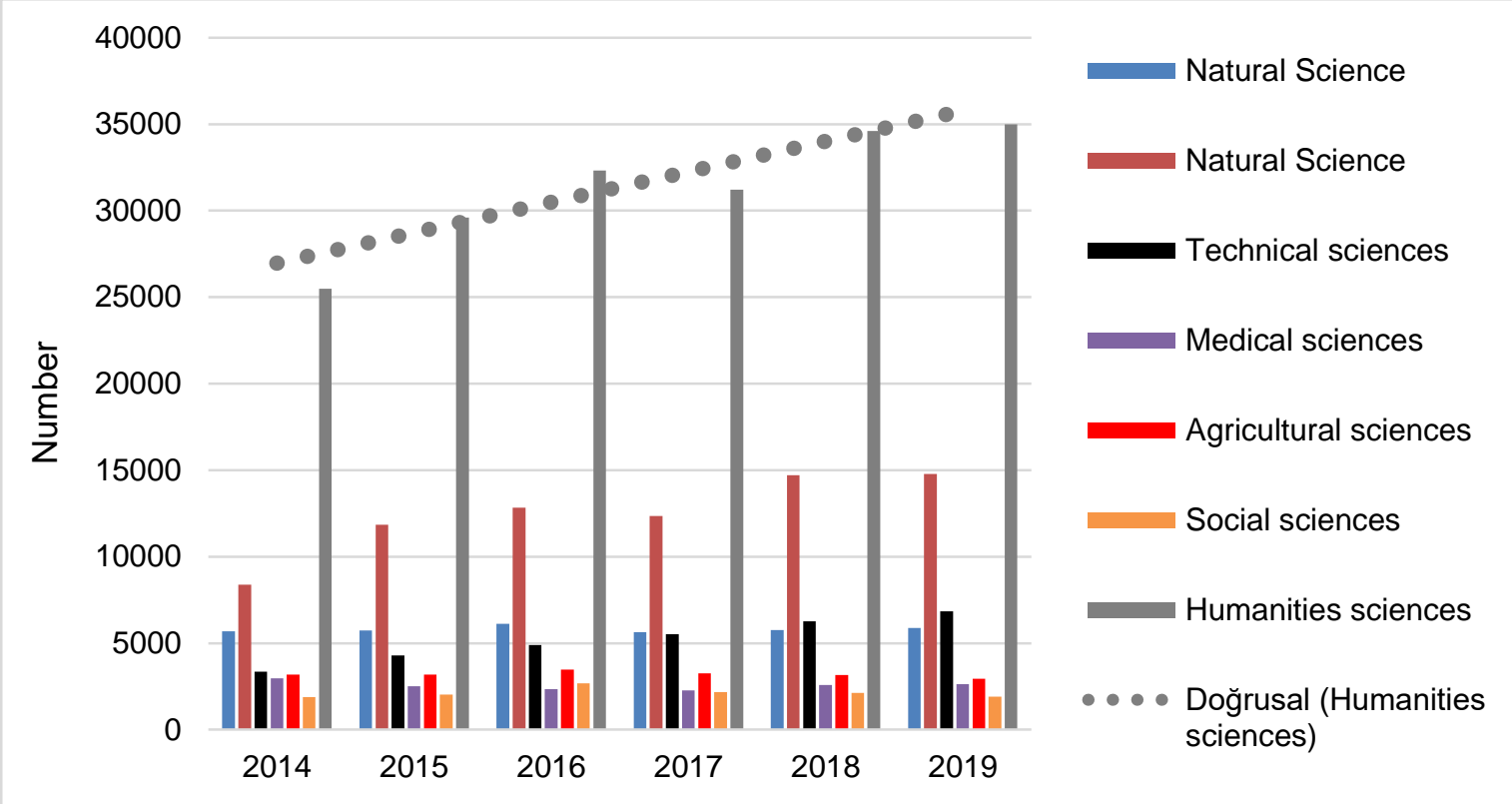

Fig. 1. The number of staff employed with scientific research and development in Bulgaria for the period 2014-2019

Notwithstanding the differences in the relative shares of people engaged in $R \& D$, account must be taken of the positive trend of their overall increase. At the same time, the analysis of data on the field of social sciences shows that by the middle of the period (2016) there was an increase, after which the trend was decreasing. As a result, the number of people engaged in research in social sciences decreased by just over $7 \%$ in 2019 (see Fig. 2).

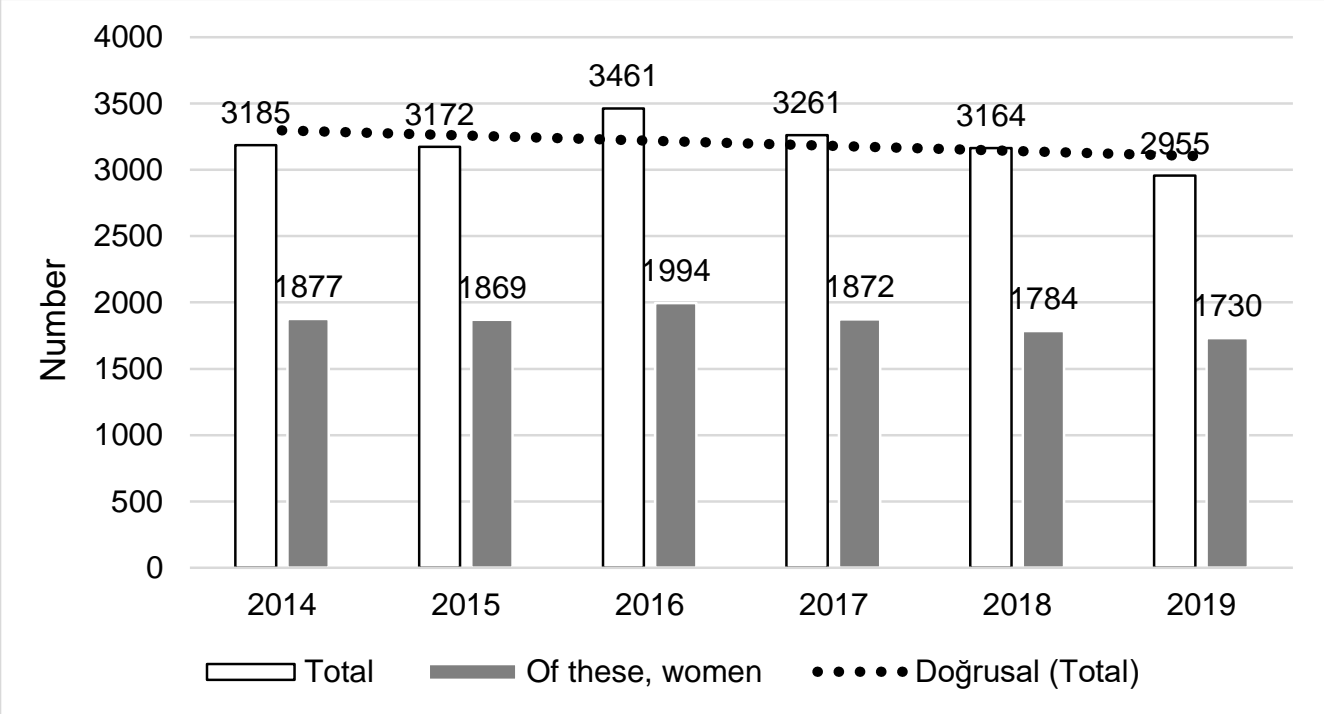

Fig. 2. Dynamics of employed staff with R\&D in social sciences in Bulgaria for the period 2014-2019²

The opportunities provided by the EU Structural Investment Funds allow for the development of vices for the

\footnotetext{
${ }^{1}$ The figure was developed based on data from https://infostat.nsi.bg

${ }^{2}$ The figure was developed based on data from https://infostat.nsi.bg
} 
construction of research infrastructures, bringing together the capabilities of different specialists. From the point of view of social sciences, this represents a favorable incentive for the collaboration of economists, lawyers, political scientists, sociologists, etc., who together can conduct complex studies, the results of which allow for the definition of guidelines for further changes. At this stage, only three infrastructure formations (consortia) in the field of social sciences have been formed in Bulgaria, namely:

- National interdisciplinary research e-infrastructure for culture, humanitarianism and integration and development of electronic resources for Bulgarian language (ClaDa-BG) with Coordinator Institute for Information and Communication Technologies at the Bulgarian Academy of Sciences (BAS).

- European Social Research - Social Research Network of Regional Importance (ESS) with Coordinator University of National and World Economy (UNWE).

- Study of Health, Aging and Retirement in Europe (SHARE ERIC Bulgaria) with Coordinator Institute of Philosophy and Sociology at BAS.

Although the coordinators of these consortia are concentrated in the capital, we must point out that in the first consortium as participants there are organizations, including universities, from different regions of the country.

The ClaDa-BG Consortium was created to ensure public access to specially developed electronic structured data and automatic processing programs for the Bulgarian language. The language technologies developed within the project are used for the processing of modern texts, as well as historical and specialized texts in specific fields such as law, scientific publications, etc. The main purpose of these technologies is to extract knowledge from texts in order to be applied in carrying out research in the field of social sciences and humanitarianism, in the process of creating the Knowledge Network for Bulgaria, for indexing the stored documents. The results of ClaDa-BG contribute to the field of education, social and state policies, the electrified government, tourism, etc., providing various related sources of information.

Since 2002, a European Social Survey (ESS) has been conducted, in which a nationally representative opinion survey is organized and carried out every two years in the EU Member States. It is based on international scientific standards in social research, compliance with which ensures reliability, completeness, credibility, and international comparability of results. Currently, five ESS waves have taken place in Bulgaria $(2006,2008,2010,2012,2018)$, and participation in wave 10 (2020-2021) is also expected. in the surveys conducted, European and in particular Bulgarian citizens share their views and assessments on key areas of socio-political life in the country and Europe. Ess-BG's performance and disclosure help to raise awareness and support the justification of policies and solutions in many areas, including security, education, health, migration, poverty, social inclusion, etc.

The SHARE Consortium is defined as the largest pan-European quantitative panel study of social sciences, unique in nature globally and possessing the ability to support research in the field of social, health, and economic development of the EU Member States and Israel. Bulgaria participates for the first time in SHARE in 2016-2018. The study is representative in nature, providing information with public access in terms of childhood, work history, health, retirement, social circumstances within human life, cognitive ability, and the strength of handgrip. In 2018-2022 Bulgaria participates in the collection of share data for the 8th and 9th wave, which will provide multidisciplinary data on aging, health, employment status, unemployment, and retirement for Bulgarians 50 years and older of unique character. In connection with the 2020 COVID-19 pandemic, a special "SHARE COVID-19" questionnaire has also been added to help raise data on how atrisk groups of older people cope in socio-economic and health terms with the pandemic.

There are serious differences in Bulgaria, as a result of which the economic development of the regions differs. The south-west planning area, where research infrastructure in the fields of physical sciences, material science, and engineering is distinguished with the best achievement and overall coverage of scientific fields; medical and agricultural sciences; social sciences and humanities; E-infrastructures. This is also the area in which the capital of Bulgaria is located, which to a certain extent predetermines the concentration of more resources of a different nature. In the other five planning regions, the strand focuses on some of the scientific fields, with the least development characterizing the North-West Planning Area, where research infrastructure can only be talked about in the field of medicine and agricultural sciences. For their part, social sciences and human resources have priority in the Southwest and south-central region and partly in the North East for planning. It is also noticeable that the social sciences and humanities are rather underestimated at this stage, with the focus on building e-infrastructure for multidisciplinary, physical, material sciences, and engineering. The NPK draws particular attention to the fact that the construction of scientific and technological centers is done through funds from the European Structural and Investment 
Funds, through funding in the field of natural sciences, e-infrastructures, grains, and food, which are a priority for the economy. At the same time, research in the field of social sciences and the environment is defined as a commitment to the national budget of the country. Given Bulgaria's limited capabilities in terms of its size in these sciences, further efforts are needed towards the construction of a favorable scientific infrastructure that will bring together the efforts of more research and educational institutions. The development of social sciences, the implementation of research, and the promotion of results is a prerequisite for improving the economic performance of the country.

Those features of the scientific infrastructure show that the success of research structures is predetermined by the participation of representatives of different scientific fields, be they individuals or entire organizations. Therefore, creating a favorable environment for successful research implies the implementation of the open innovation approach. By their very nature, open innovation is associated with the abolition of strict boundaries of entities by "opening" their entrance and exit for novelties (Ivanova, 2019:42). This in turn is an important prerequisite for research and development, especially since, as they point out, Coras and Tantau (2014) the main driver of open innovation is communication between stakeholders. They can rely on both internal capabilities and external support in various forms, including specialized laboratories, research centers, and premises, independent scientists (Salter et al., 2014). On the other hand, we will point out that there are researchers J. Rodríguez end A. Lorenzo (2011), M. Hossain (2013), E. Tauraitè-Kavai (2014), which emphasize the fact that open innovation encompasses an incoming and outgoing exchange of knowledge. At the heart of this lies the understanding that technology alone is not enough to provide reliable long-term competitive advantages. In this regard, there is an opinion in the specialized literature that "open innovation leads to the elimination of organizational boundaries for the origin of innovations - inside or outside the organization" (Breuning et al., 2014:47). Accelerating the innovation process by mobilizing internal and external resources is accepted as a guarantee for successful innovation and research efforts. A similar approach to innovation, both in terms of their creation and subsequent implementation, is also inherent in the NPK. It is practically very complicated for each of the scientific fields to work for itself. Success depends on bringing together the efforts of different stakeholders, which also underpins the understanding of open innovation. The external environment and its specificities may favor or hinder the innovative activities of scientific infrastructures. The creation of consortia, comprising representatives of different institutions and organizations, enables the pooling of the forces and knowledge of people with different scientific and research competencies who can jointly create new knowledge for the benefit of society, i.e. to create, implement, implement and disseminate innovative ideas.

\section{ACKNOWLEDGEMENT}

At the heart of the scientific infrastructure lies the "knowledge triangle" - education, research, and innovation, to which society is already added, as a result of which there is talk of a "quadruple spiral". These factors are key to shaping a dynamic economic model for sustainable development and are defined as an effective way to concentrate on scientific potential and resources. Bulgaria as an EU member must follow its priorities and be part of the European Research Area. The well-established scientific infrastructure practically supports the process of creating and disseminating new knowledge in the field of fundamental and applied research. This makes it possible to resolve interdisciplinary issues, as well as commercialize the results of the research and transform them into innovative products and services. Financially, investments in scientific infrastructure must be planned and developed, looking for ways to make effective and integrated use of possible national and European funds. The implementation of the principle of open innovation in the field of research work will allow the involvement of different stakeholders to be involved, as well as support the process of creating, acquiring, and disseminating intellectual property in a regulated manner. It is important to promote the results of the research carried out. The field of social sciences is characterized by some shift in the background compared to areas such as medicine, electronics, energy, information technology, etc. As we have already pointed out, the proportion of people engaged in R\&D in the field of social sciences is also lower, which creates additional constraints. Nevertheless, the social sciences have their place in the NRSI in Bulgaria.

\section{REFERENCE LIST}

Breuning, K. et. al. (2014). Incentives and performance measures for open innovation practices. // Measuring Business Excellence, [Online] Vol. 18, No. 1, pp. 45-54

Coras, E., A. Tantau. (2014). Open innovation - the good, the bad, the uncertainties. // The USV Annals of 
Economics and Public Administration. [Online].Vol. 14, Issue 1 (19), pp. 38-47

Hossain, M. (2013). Open innovation: so far and a way forward. // World Journal of Science, Technology and Sustainable Development. [Online]. Vol. 10, No. 1, pp. 30-41

Ivanova, R. (2019). Management Aspects of Open Innovation and the Environment for its Use in Bulgaria. Varna: Science and Economics, Library "Prof. Tsani Kalyandzhiev ", Book 57

National Roadmap for Scientific Infrastructure. [Online] Available from: ec.europa.eu/bulgaria_national_roadmap_2017_bg [Accessed October 2020]

pr_NPKNIfrast-i-dokladMS_08102020[Online] Available from: www.mon.bg/pr_NPKNIfrast-idokladMS_08102020 [Accessed October 2020]

Results of the diagnostic examination of the scientific infrastructure and equipment in the Republic of Bulgaria [Online] Available from: www.mon.bg/upload/Diagnostic_BG [Accessed October 2020]

Rodríguez, J., A. Lorenzo. (2011). Open Innovation: Organizational Challenges of a New Paradigm of Innovation Management. // European Research Studies. [Online]. Vol. XIV, Issue (1), pp. 75-82 [Accessed февруари 2016]

Salter, A., P. Criscuolo, A. Ter Wal. (2014). Coping with Open Innovation: Responding to the challenges of external engagement in R\&D. // California Management Review. [Online]. Vol. 56, N 2, Winter 2014, pp. 77-94. Available from: cmr.berkeley.edu [Accessed February 2016]

Tauraitè-Kavai, E. (2014). Knowledge Management in Open Innovation Context. // European Conference on Knowledge Management. [Online]. 3, September, pp. 1301-1305 [Accessed March 2016]

https://clada-bg.eu/

https://infostat.nsi.bg/ [Accessed November 2020]

http://www.strategy.bg/StrategicDocuments/View.aspx?ld=919 